\title{
Methicillin-resistant Staphylococcus aureus nosocomial pneumonia: role of linezolid in the People's Republic of China
}

This article was published in the following Dove Press journal:

ClinicoEconomics and Outcomes Research

24 March 2016

Number of times this article has been viewed

\section{Beth Lesher' \\ Xin Gao' \\ Yixi Chen ${ }^{2}$ \\ Zhengyin $\mathrm{Liu}^{3}$}

'Pharmerit International, Bethesda, MD, USA; 2Pfizer Investment Co. Ltd, ${ }^{3}$ Department of Infectious Disease, Peking Union Medical College Hospital, Chinese Academy of Medical Sciences and Peking Union Medical College, Beijing, People's Republic of China

Correspondence: Beth A Lesher Pharmerit International, 4350 East-West Highway, Suite 430, Bethesda, MD 208I4, USA

$\mathrm{Tel}+\mathrm{I} 2408219665$

Fax + | $24082 \mid 1296$

Email blesher@pharmerit.com
Abstract: The burden of methicillin-resistant Staphylococcus aureus (MRSA) nosocomial pneumonia in the People's Republic of China is high, with methicillin-resistance rates greater than $80 \%$ reported for patients with $S$. aureus pneumonia treated in intensive care units. Historically, vancomycin was the treatment of choice for patients with hospital-acquired MRSA infections. Recent evidence suggests that the minimum inhibitory concentration for vancomycin is increasing. Additionally, patients treated with vancomycin require monitoring of vancomycin trough concentrations and can develop nephrotoxicity. Linezolid is a treatment option for patients with hospital-acquired MRSA infections that can be administered either intravenously or orally. Analysis of data from a worldwide linezolid surveillance program initiated in the year 2004 shows no evidence of increasing linezolid minimum inhibitory concentrations. The clinical efficacy of linezolid for patients with gram-positive, including MRSA, nosocomial pneumonia, was evaluated in numerous studies. In general, results from these studies show higher or similar clinical success with no mortality difference for linezolid compared to vancomycin treated patients. Results from a Phase IV study enrolling patients with MRSA-confirmed nosocomial pneumonia suggest higher clinical cure rates for linezolid compared to vancomycin treated patients. Although acquisition costs are higher for linezolid compared to vancomycin therapy, evidence suggests similar overall medical costs. Cost-analysis results from a Chinese perspective show that linezolid dominated vancomycin therapy for MRSA nosocomial pneumonia in $\sim 35 \%$ of bootstrap simulations whereas vancomycin dominated linezolid in less than $2 \%$ of bootstrap simulations. In summary, results from both clinical and economic studies, including studies conducted from a Chinese perspective, support the use of linezolid for the treatment of patients with MRSA nosocomial pneumonia.

Keywords: anti-infectious, methicillin-resistance, nosocomial pneumonia, health economics

\section{Introduction}

Globally, antibacterial resistance negatively affects patient outcomes and health care costs. ${ }^{1}$ The ability to treat many common health care- and community-associated infections is threatened by the development of resistant bacteria. ${ }^{1}$ Staphylococcus aureus is an example of a pathogenic, gram-positive organism that over time developed resistance to many available antibiotics, including penicillin and beta-lactamase stable penicillins such as methicillin and oxacillin.

$S$. aureus is frequently found on the skin and in the nose and is a common cause of skin and soft tissue, bone, bloodstream, and postoperative wound infections. The percentage of $S$. aureus resistant to methicillin is greater than $20 \%$ in many geographical regions and exceeds $80 \%$ in some World Health Organization regions. ${ }^{1}$ 
Evidence suggests an increasing role of methicillin-resistant $S$. aureus (MRSA) in patients with hospital-acquired pneumonia (HAP). ${ }^{2}$ Results from several studies specific to the People's Republic of China or the Asia region show that $S$. aureus plays a major role in patients with HAP, including ventilator associated pneumonia (VAP). ${ }^{3-5}$ Results from a systematic review and meta-analysis show that $S$. aureus is the fourth most frequently isolated pathogen, and $82.9 \%$ of $S$. aureus isolates were methicillin-resistant in patients with ICU-acquired pneumonia or VAP in the People's Republic of China. ${ }^{5}$ Whereas community-acquired $S$. aureus strains tend to maintain sensitivity to non-beta-lactam antibiotics such as clindamycin and trimethoprim/sulfamethoxazole, hospital-acquired strains are often multidrug-resistant $t^{3,5-7}$ with few treatment options.

Vancomycin and linezolid are treatment options for patients with gram-positive infections including those caused by MRSA. Results from a published Phase IV trial $\left(Z_{y v o x}{ }^{\circledR}\right.$ in the Treatment of Subjects with Nosocomial Pneumonia Proven to be Due to Methicillin-Resistant Staphylococcus aureus [ZEPHyR]) suggest higher clinical success and similar mortality in patients with MRSA nosocomial pneumonia treated with linezolid compared to vancomycin therapy. ${ }^{8}$ Although acquisition costs are higher for linezolid than vancomycin, analysis of health care resource utilization from a Chinese perspective using outcomes data from the ZEPHyR trial found no difference in overall medical costs between linezolid and vancomycin treated patients. ${ }^{9}$ Results from a multicenter, retrospective, observational study similarly show higher clinical success and similar mortality in patients with MRSA nosocomial pneumonia treated with linezolid compared to vancomycin therapy. ${ }^{10}$ In contrast, results from a retrospective study conducted in the People's Republic of China show similar clinical success but higher mortality in patients empirically treated with linezolid compared to vancomycin for HAP; total hospital costs trended lower for vancomycin compared to linezolid treated patients although this difference was not significant. ${ }^{11}$ The objective of this review is to summarize the available clinical and economic information on the treatment of MRSA nosocomial pneumonia with a focus on linezolid and vancomycin as well as economic and clinical data available for the People's Republic of China.

\section{Methods}

A PubMed search was performed to identify studies reporting the incidence of MRSA in the People's Republic of China for the years 2004 through 2014. Of the 179 citations identified, ten studies reported incidence data for MRSA isolates in the People's Republic of China. ${ }^{6,7,12-19}$ A PubMed search was also performed to identify comparative studies and meta-analyses evaluating linezolid and vancomycin therapy in adult patients with nosocomial pneumonia. Of the 35 citations identified, 24 studies or meta-analyses ${ }^{8,10,11,31-51}$ compared the economic or clinical outcome of patients treated with either linezolid or vancomycin therapy and were included in this review. An additional economic study was identified through a Google search. ${ }^{9}$

\section{MRSA incidence in the People's Republic of China Overall}

Results from studies conducted throughout the People's Republic of China from the year 2004 through the year 2011 suggest that the burden of MRSA is high, ranging from $~ 27 \%$

Table I Summary of results for studies reporting Staphylococcus aureus resistance to methicillin in the People's Republic of China

\begin{tabular}{|c|c|c|c|c|c|}
\hline \multirow[t]{2}{*}{ Reference } & \multirow{2}{*}{$\begin{array}{l}\text { Chinese } \\
\text { sites, } n\end{array}$} & \multirow{2}{*}{$\begin{array}{l}\text { Date isolates } \\
\text { obtained }\end{array}$} & \multirow{2}{*}{$\begin{array}{l}\text { Infection } \\
\text { type }\end{array}$} & \multicolumn{2}{|l|}{ S. aureus } \\
\hline & & & & Isolates, $\mathrm{n}$ & MR isolates, $n(\%)$ \\
\hline Chen et al ${ }^{12}$ & 4 & $2009-2011$ & BS & 108 & $62(57.4)$ \\
\hline Chen et $\mathrm{a}^{6, \mathrm{a}}$ & 13 & 2011 & BS, HAP, IA & NR & $N R(64.4)$ \\
\hline Jones et $\mathrm{a}^{13}$ & 12 & 2011 & $\mathrm{BS}, \mathrm{RT}$, SSS & 343 & $157(45.8)$ \\
\hline \multirow[t]{2}{*}{ Lu et $\mathrm{al}^{14, \mathrm{a}}$} & 18 & $2007-2008$ & BS & 37 & $20(54.1)$ \\
\hline & & $2009-2010$ & & 170 & $62(36.5)$ \\
\hline Reinert et $\mathrm{al}^{15}$ & 2 & 2004-2006 & Various & NR & NR (59.1) \\
\hline Sun et $\mathrm{al}^{16, \mathrm{a}}$ & 12 & 2009 & NR & 466 & $211(45.3)$ \\
\hline Wang et $\mathrm{al}^{17}$ & 16 & 2008 & NR & 798 & $403(50.5)$ \\
\hline Wei et $\mathrm{al}^{18}$ & I & $2008-2011$ & Various & 690 & $391(56.7)$ \\
\hline \multirow[t]{3}{*}{ Zhao et $\mathrm{al}^{7}$} & 12 & $2005-2010$ & Various & 2,245 & $\mathrm{I}, 050(46.8)$ \\
\hline & & & Respiratory & 735 & $496(67.5)$ \\
\hline & & & SSS & 771 & $211(27.4)$ \\
\hline Zou et al ${ }^{19}$ & 11 & $2006-2008$ & Various & 293 & $190(64.8)$ \\
\hline
\end{tabular}

Notes: a Data taken from abstract; article in Chinese.

Abbreviations: BS, bloodstream; HAP, hospital-acquired pneumonia; IA, intra-abdominal; MR, methicillin-resistant; NR, not reported; RT, respiratory tract; SSS, skin and skin structure. 
to $65 \%$ (Table 1). ${ }^{6,712-19}$ Analysis of $S$. aureus resistance in Chinese cities shows considerable variability ranging from a low of less than $40 \%$ at Beijing Union Medical College Hospital and Sir Run Run Shaw Hospital of Zhejiang University Medical College to a high of more than $80 \%$ at Beijing Hospital. ${ }^{20}$

\section{Nosocomial pneumonia}

The prevalence of MRSA in the People's Republic of China may be higher in patients with respiratory than other types of infections. ${ }^{3,5-7}$ Results from a meta-analysis and systematic review of studies published between January 2007 and May 2012 show that $S$. aureus was the fourth most common cause of pneumonia in patients hospitalized in intensive care units in the People's Republic of China; $82.9 \%$ of $S$. aureus isolates were methicillin-resistant. ${ }^{5}$ Results from a prospective surveillance study conducted in ten Asian countries by the Asian Network Surveillance of Resistant Pathogens (ANSORP) group for the years 2008 to 2009 were similar. ${ }^{3}$ For the ten Asian locales included in this study, S. aureus was the most common cause of HAP accounting for $15.8 \%$ of all HAP cases and the third most common cause of VAP accounting for $12.2 \%$ of all VAP cases; $82.1 \%$ of $S$. aureus isolates were resistant to methicillin. Analysis of data from the People's Republic of China only found that $S$. aureus was the second most common cause of HAP accounting for $16.0 \%$ of all HAP cases and the third most common cause of VAP accounting for $24 \%$ of all VAP cases; $82.4 \%$ of isolates were resistant to methicillin. Lastly, results from a prospective multicenter study performed in 13 Chinese urban tertiary hospitals showed that $S$. aureus was the third most common cause of HAP accounting for $13.4 \%$ of all HAP cases, and the second most common cause of VAP accounting for $21.4 \%$ of all VAP cases; $87.8 \%$ of isolates were resistant to methicillin. ${ }^{4}$

\section{MRSA pneumonia treatment Treatment recommendations}

Recommendations for the treatment of $\mathrm{HAP}^{22}$ and $S$. aureus nosocomial pneumonia ${ }^{23}$ for the Asia region are available in the medical literature. These guidelines account for not only differences in HAP epidemiology and microbiology but also the use, availability, and cost of antibiotic therapies between the Asia region and those covered by other published guidelines such as the US ${ }^{24,25}$ and England. ${ }^{26}$

\section{Asian HAPWorking Group}

The Asian HAP Working Group published treatment recommendations for patients with HAP in Asian countries in the year 2008. ${ }^{22}$ These guidelines state that inclusion of glycopeptide or linezolid therapy is a matter of clinical judgment and local sensitivity profiles but should be considered for patients with late-onset HAP or early- or late-onset VAP. Vancomycin and teicoplanin are the recommended first-line therapies; linezolid and tigecycline are the recommended second-line therapies. The working group suggested reserving linezolid for second-line MRSA therapy to avoid selection of resistant strains.

\section{Asian Consensus Taskforce on MRSA Nosocomial Pneumonia}

More recently, the Asian Consensus Taskforce on MRSA Nosocomial Pneumonia published treatment recommendations in the year 2014 to provide clinicians guidance on treating adult patients with MRSA nosocomial pneumonia in Asia taking into account regional data on MRSA colonization and vancomycin minimum inhibitory concentrations (MICs). ${ }^{23}$ These recommendations stress the importance of timely appropriate antibiotic therapy with either linezolid or vancomycin for patients with suspected MRSA nosocomial pneumonia. Linezolid is recommended for patients with a high risk of vancomycin failure or intolerance defined as the following: prevailing local vancomycin MIC of $1.5 \mathrm{mg} / \mathrm{L}$ or greater, age of 65 years or greater, reduced renal function, concurrent administration of nephrotoxic drugs, body mass index greater than $30 \mathrm{~kg} / \mathrm{m}^{2}$, or prior vancomycin therapy. Vancomycin is recommended for patients not at risk of vancomycin failure or intolerance.

\section{Treatments}

\section{Vancomycin}

Vancomycin, a glycopeptide antibiotic, traditionally was the treatment of choice for patients with MRSA infections including MRSA pneumonia. Recent evidence suggests, however, that the vancomycin MIC for staphylococci is increasing which may ultimately result in an increase in vancomycin-resistant staphylococci. ${ }^{27}$ Results from a study conducted in six Chinese hospitals suggest that the vancomycin MIC for MRSA isolates is increasing. For the years 2006 to 2011, the MIC for vancomycin significantly increased over time from 0.906 to $1.040 \mathrm{mg} / \mathrm{L}$ $(P<0.001$ for trend). Likewise, the percentage of MRSA with a vancomycin MIC greater than $1 \mathrm{mg} / \mathrm{L}$ increased from $26.0 \%$ in the year 2006 to $42.8 \%$ in the year $2011(P<0.005)$. The probability of achieving optimal vancomycin concentrations when the MIC is greater than $1 \mathrm{mg} / \mathrm{L}$ at a vancomycin dose of 0.5 to $2 \mathrm{~g}$ every 12 hours is unlikely. ${ }^{23} \mathrm{~A}$ creep in the MIC for teicoplanin was also reported increasing from $0.749 \mathrm{mg} / \mathrm{L}$ in the year 2009 to $0.973 \mathrm{mg} / \mathrm{L}$ in the year 2011 . 
Other disadvantages of vancomycin therapy include slow bactericidal activity, minimal penetration into lung tissue, and nephrotoxicity. ${ }^{23}$ Current recommendations for patients with nosocomial pneumonia are to achieve vancomycin trough concentrations of 15 to $20 \mathrm{mg} / \mathrm{L}$ to maximize pharmacokinetic and pharmacodynamic properties. ${ }^{28}$ Nephrotoxicity with vancomycin therapy appears to increase with trough concentrations greater than $10 \mathrm{mg} / \mathrm{L}$, especially in patients receiving concurrent nephrotoxic therapies. ${ }^{28}$

\section{Linezolid}

Linezolid is a synthetic oxazolidione antibacterial agent indicated for the treatment of vancomycin-resistant Enterococcus faecium infections, complicated and uncomplicated skin and soft tissue infections caused by methicillin sensitive S. aureus (MSSA) or Streptococcus pyogenes, complicated skin and soft tissue infections caused by MRSA or Streptococcus agalactiae, and nosocomial pneumonia caused by MRSA, MSSA, or Streptococcus pneumonia including multidrug-resistant strains. Linezolid is available in both an intravenous and oral form; the oral form is $100 \%$ bioavailable allowing for a seamless transition from intravenous to oral therapy. Hematologic toxicity can occur with linezolid therapy; however, this typically occurs with long-term administration.

Linezolid activity against gram-positive organisms is monitored through the Zyvox ${ }^{\circledR}$ Annual Appraisal of Potency and Spectrum (ZAAPS) program, with data obtained from 73 medical centers in 33 countries (not including the US) from five continents and available for the years 2004 through 2013. Since inception of this worldwide surveillance program, linezolid susceptibility remains greater than $99.9 \%$ with no evidence of MIC creep. ${ }^{29,30}$

\section{Clinical evidence, linezolid versus vancomycin ZEPHyR trial}

The objective of the ZEPHyR trial was to compare the efficacy, safety, and tolerability of linezolid $(n=172)$ compared to vancomycin $(n=176)$ therapy in adult patients with cultureproven MRSA nosocomial pneumonia. ${ }^{8}$ This multinational, prospective, randomized, double-blind, multicenter study randomized patients to either intravenous linezolid $600 \mathrm{mg}$ every 12 hours or intravenous vancomycin $15 \mathrm{mg} / \mathrm{kg}$ every 12 hours for 7 to 14 consecutive days. Vancomycin dosing was adjusted based on renal function and trough concentrations.

More patients treated with linezolid ( $n=95,57.6 \%$ ) compared to vancomycin $(n=81,46.6 \%)$ were clinically cured at end of study $(P=0.042)$. In general, clinical success rates were $10 \%$ to $15 \%$ higher in linezolid compared to vancomycin treated patients in most populations and subgroups evaluated including patients with a vancomyin MIC of $1 \mu \mathrm{g} / \mathrm{mL}$ (61.5\% vs 47.8\%; 95\% confidence interval [CI] for difference, 1.6-25.8) and APACHE II score <20 (61.6\% vs 48.8\%; 95\% CI for difference, 0.2-25.5). Microbiological success (either eradication or presumed eradication) was also greater in linezolid than vancomycin treated patients at both end of study (58.1\% vs 47.1\%; 95\% CI: $0.4-21.5)$ and end of treatment (81.9\% vs $60.6 \%$; 95\% CI: $12.3-30.2)$ suggesting that MRSA clearance may be more complete with linezolid than vancomycin therapy.

In the intent to treat population, investigator-reported renal events defined as one or more of the following: renal failure, renal impairment, and azotemia, were two times more common in vancomycin (7.3\%) compared to linezolid (3.7\%) treated patients. ${ }^{8}$ Investigator-reported rates of anemia, neutropenia, and thrombocytopenia were similar between the linezolid and vancomycin groups.

All-cause, 60-day mortality in both the intent to treat and modified intent to treat populations was similar between the linezolid (15.7\%) and vancomycin (17.0\%) treatment groups.

\section{Phase III and other sponsor supported randomized trials}

Two additional sponsor supported studies were conducted in adult patients with nosocomial pneumonia. ${ }^{31,32}$ Both of these studies were randomized, double-blind registration studies that compared linezolid with vancomycin for the empiric treatment of nosocomial pneumonia. Patients were randomly assigned to receive either linezolid $600 \mathrm{mg}$ intravenously every 12 hours or vancomycin $1,000 \mathrm{mg}$ intravenously every 12 hours (dose adjusted per an unblinded investigator). Aztreonam therapy was permitted in both treatment groups for gram-negative coverage.

Results from both studies show similar clinical cure and pathogen eradication rates for linezolid and vancomycin treated patients (Table 2). Secondary efficacy outcomes evaluated such as clinical signs and symptoms of pneumonia, chest radiograph, temperature, respiratory rate, and white blood cell count were also similar between the treatment groups. There were no significant differences in the number of deaths between the treatment groups in either study.

In contrast to the ZEPHyR study in which enrolled patients had culture proven MRSA pneumonia, patients were enrolled in these Phase III studies for the empiric treatment of nosocomial pneumonia. Approximately $30 \%$ 
Table 2 Clinical cure and organism eradication rates for linezolid and vancomycin treatment groups in randomized studies enrolling patients with known or suspected gram-positive nosocomial pneumonia $^{\mathrm{a}}$

\begin{tabular}{|c|c|c|c|}
\hline \multirow{2}{*}{$\begin{array}{l}\text { Population or } \\
\text { subgroup }\end{array}$} & \multicolumn{2}{|c|}{ Patients, n/N (\%) } & \multirow{2}{*}{$\begin{array}{l}95 \% \mathrm{Cl} \text { for } \\
\text { difference }^{\mathrm{c}}\end{array}$} \\
\hline & Linezolid & Vancomycin & \\
\hline \multicolumn{4}{|l|}{ Rubinstein et $\mathrm{a}^{31}$} \\
\hline \multicolumn{4}{|l|}{ Clinical cure } \\
\hline ITT & $86 / 161$ (53.4) & 74/I42 (52.1) & NR \\
\hline $\mathrm{CE}^{\mathrm{a}}$ & $71 / 107$ (66.4) & $62 / 91(68.1)$ & -14.9 to $1 \mathrm{I} .3$ \\
\hline$M E^{b}$ & $36 / 53(67.9)$ & $28 / 39$ (71.8) & -22.8 to 15.0 \\
\hline \multicolumn{4}{|l|}{ Organism eradication } \\
\hline Staphylococcus aureus & $25 / 4 I(6 I .0)$ & $15 / 23(65.2)$ & NR \\
\hline MR S. aureus & $15 / 23(60.9)$ & $7 / 9(77.8)$ & NR \\
\hline $\begin{array}{l}\text { Streptococcus } \\
\text { pneumoniae }\end{array}$ & $9 / 9(100)$ & $9 / 9(100)$ & NR \\
\hline \multicolumn{4}{|l|}{ Wunderink et $\mathrm{a}^{33}$} \\
\hline \multicolumn{4}{|l|}{ Clinical cure } \\
\hline ITT & $135 / 256(52.7)$ & I28/245 (43.5) & -8.3 to 9.2 \\
\hline $\mathrm{CE}^{\mathrm{a}}$ & II4/I68 (67.9) & III/I7I (43.5) & -7.1 to 13.0 \\
\hline ME & $47 / 76(61.8)$ & $42 / 78(92.3)$ & -6.9 to 24.2 \\
\hline \multicolumn{4}{|l|}{ Organism eradication } \\
\hline S. aureus & $28 / 52(53.8)$ & $27 / 62(43.5)$ & -8.0 to 28.6 \\
\hline MR S. aureus & $12 / 19(63.2)$ & $10 / 23(43.5)$ & NR \\
\hline S. pneumoniae & 14/18 (77.8) & $12 / 13(92.3)$ & -38.6 to 9.5 \\
\hline \multicolumn{4}{|l|}{ Lin et $\mathrm{al}^{35}$} \\
\hline \multicolumn{4}{|l|}{ Effective treatment } \\
\hline \multicolumn{4}{|l|}{ rate } \\
\hline EOT & $22 / 28(78.6)$ & $18 / 34(52.9)$ & 2.99 to 48.3 \\
\hline FU & $19 / 26(73.1)$ & $18 / 33(54.5)$ & -5.5 to 42.6 \\
\hline \multicolumn{4}{|l|}{ Pathogen eradication } \\
\hline \multicolumn{4}{|l|}{ rate } \\
\hline $\begin{array}{l}\text { Gram-positive } \\
\text { pneumonia }\end{array}$ & 17/22 (77.3) & I5/28 (53.6) & -1.75 to 49.16 \\
\hline S. aureus & 14/18 (77.8) & $|I / 2|(52.4)$ & NR \\
\hline
\end{tabular}

Notes: anly data presented for patients with known or suspected grampositive pneumonia; bdata presented as $n / N$ where $n$ equals the number of patients with a response and $\mathrm{N}$ equals the number of patients evaluated; ${ }^{~} \mathrm{Cl}$ for difference between clinical success rates for linezolid minus those for vancomycin. Abbreviations: $\mathrm{Cl}$, confidence interval; $\mathrm{CE}$, clinically evaluable; EOT, end of treatment; FU, follow-up; ITT, intent to treat; ME, microbiologically evaluable; MR, methicillin-resistant; NR, not reported.

to $35 \%$ of patients had a gram-positive organism identified at baseline; an additional $8 \%$ to $13 \%$ of patients had both a gram-positive and gram-negative organism identified at baseline. Data for patients with $S$. aureus pneumonia were retrospectively combined and analyzed.$^{33}$ Results from this combined analysis showed a significantly higher clinical cure rate for linezolid (36 of 61 patients; 59.0\%) compared to vancomycin (22 of 62 patients; $35.5 \%$ ) treated patients with MRSA-confirmed nosocomial pneumonia $(P<0.01)$; this difference remained significant following adjustment for differences in patient characteristics at baseline (odds ratio [OR], 3.3; 95\% CI, 1.3-8.3; $P=0.01$ ). Kaplan-Meier analyses showed a survival difference for linezolid $(80 \%)$ compared to vancomycin (63.5\%) therapy in patients with MRSA pneumonia $(P=0.03)$ which remained significant after adjusting for baseline variables (OR, 2.2; 95\% CI, $1.0-4.8 ; P=0.01)$.

A second retrospective analysis evaluated data from these two Phase III trials for patients with suspected gram-positive VAP ( $=544) ; 91$ patients had documented MRSA VAP. ${ }^{34}$ Clinical cure rates and hospital survival were higher for linezolid compared to vancomycin therapy for all populations evaluated. Results from logistic regression analyses showed that linezolid therapy was a significant predictor of clinical cure and hospital survival for all four populations evaluated.

A randomized, double-blind, Phase III study comparing linezolid and vancomycin therapy in patients with gram-positive infections was also performed at seven hospitals in the People's Republic of China. ${ }^{35}$ Patients enrolled had known or suspected gram-positive pneumonia or complicated skin and soft-tissue infections. Overall, S. aureus was the most common organism isolated at baseline; $75 \%$ of $S$. aureus isolated were resistant to methicillin. Results are summarized for patients with pneumonia only. At end of treatment and at the follow-up visit ( 7 to 28 days posttreatment), clinical cure rates were higher for patients treated with linezolid than vancomycin; microbiological eradication was also higher for patients treated with linezolid compared to vancomycin (Table 2).

Lastly, two additional sponsor supported studies randomized patients to linezolid or vancomycin therapy for treatment of known or suspected MRSA infections including patients with known or suspected MRSA pneumonia ${ }^{36}$ or MRSA VAP. ${ }^{37}$ In the known or suspected MRSA infection study, ${ }^{36}$ there was no difference in clinical cure rate (56.8\% vs $55.0 \% ; P=0.74 ; 95 \% \mathrm{CI}$ for difference -8.5 to $12.0)$ or microbiological success rate $(50.8 \%$ vs $51.7 \%$; $P=0.90 ; 95 \%$ CI for difference -13.4 to 11.7 ) between linezolid and vancomycin treated patients overall. In the MRSA VAP study,${ }^{37}$ numerically more patients treated with linezolid than vancomycin achieved microbiologic $(56.5 \%$ vs $47.4 \% ; P=0.757 ; 95 \% \mathrm{CI}-21.1$ to 39.4$)$ and clinical $(66.7 \%$ vs $52.9 \%$; $P$-value not reported) cures. Additionally, more patients treated with linezolid than vancomycin survived ( $86.7 \%$ vs $70.0 \%)$.

\section{Retrospective analyses}

Four studies retrospectively compared clinical outcomes in patients with MRSA pneumonia ${ }^{10,11,38,39}$ including two studies that compared outcomes in patients with MRSA VAP. ${ }^{10,39}$ Results from a retrospective analysis of data in 
the US Veterans Health Administration national database (January 1, 2002 to September 30, 2010) reflecting realworld clinical settings found a significantly higher clinical success rate in linezolid $(n=231)$ than vancomycin $(n=3,500)$ treated patients (adjusted hazard ratio, 1.25; CI, 1.07-1.47) with MRSA pneumonia. ${ }^{38}$ Thirty-day mortality was similar between linezolid (19.5\%) and vancomycin (20.9\%) treated patients $(P=0.56)$. In contrast, results from a retrospective study using a hospital database from a tertiary care hospital in Shanghai, People's Republic of China, showed similar clinical response rates $(31.7 \%$ vs $30.0 \%)$ and lower treatment failure rates $(45.0 \%$ vs $55.0 \% ; P=0.847)$, but higher pneumonia-related (10.0\% vs $1.7 \%$; OR, 6.425; $P=0.059)$ and all-cause mortality ( $18.3 \%$ vs $3.3 \%$; OR, 6.564; $P=0.013$ ) at hospital discharge for linezolid compared to vancomycin treated patients. ${ }^{11}$ Results from this study however, should be evaluated cautiously as differences existed between the linezolid and vancomycin matched treatment groups and enrolled patients were diagnosed with HAP, not exclusively gram-positive HAP.

Results from the two retrospective analyses in patients with MRSA VAP showed higher clinical success with no difference in mortality between linezolid and vancomycin treated patients similar to the results from the prospective studies. ${ }^{10,39}$

\section{Meta-analyses}

Although numerous meta-analyses evaluated the role of linezolid in the treatment of patients with pneumonia, ${ }^{40-49}$ only five directly compared linezolid and vancomycin therapy. ${ }^{40,41,44,47,49}$ In general, results from these analyses show similar ${ }^{40,41,47,49}$ or increased ${ }^{44}$ clinical success with linezolid compared to vancomycin therapy (Table 3 ). Only two analyses compared mortality rates between patients treated with vancomycin and linezolid therapy for nosocomial pneumonia; no difference in mortality rates was found..$^{47,49}$

\section{Analysis of clinical evidence}

Numerous studies evaluated the efficacy and safety of linezolid in the treatment of patients with suspected or proven grampositive pneumonia. , $^{8,31,32,35-37}$ In general, results from these studies show higher or similar clinical success for linezolid versus vancomycin therapy with no difference in mortality.

Differences in outcomes reported for these studies can potentially be explained by differences in populations evaluated. Similar or higher clinical success for linezolid versus vancomycin therapy was reported in studies that enrolled patients with culture-proven MRSA HAP or at a minimum documented or presumed gram-positive HAP.

Lower clinical response rates were reported in the realworld study conducted in the People's Republic of China. ${ }^{11}$ In this study, linezolid and vancomycin therapy were initiated for the empiric treatment of HAP; few patients underwent microbiologic testing. The lower clinical response rates reported for this study suggest that at least some linezolid and vancomycin treated patients had non-gram-positive HAP which is consistent with epidemiological data showing that the majority of HAP cases in the People's Republic of China are due to gram-negative organisms. ${ }^{4,5}$ The authors of this study stated that the routine microbiological assessment of patients with HAP is not routinely performed in Chinese tertiary care hospitals. A clearer understanding of the antimicrobial treatment of patients with HAP in Chinese tertiary care hospitals is needed in order to promote the rational use of antimicrobials in this setting.

\section{Economic evidence ZEPHyR analysis}

The economic impact of linezolid compared to vancomycin therapy for the treatment of gram-positive nosocomial pneumonia was evaluated in several clinical trials including the ZEPHyR trial. Economic results from the ZEPHyR trial for patients with MRSA nosocomial pneumonia show similar overall costs for linezolid $(\$ 45,004)$ and vancomycin $(\$ 44,897)$ treated patients despite linezolid's higher drug acquisition price (Figure 1). ${ }^{50}$ The higher drug cost for linezolid was offset by lower non-significant cost differences in reduced bed days and dialysis utilization for linezolid compared to vancomycin therapy. Results from this cost-effectiveness analysis show that linezolid treatment provides better efficacy with lower or only slightly higher costs than vancomycin treatment for the majority (73\%) of bootstrap samples evaluated; linezolid treatment dominated vancomycin treatment in $24 \%$ of bootstrap samples having both better efficacy and lower costs. In the ZEPHyR trial, total costs were higher for patients who developed renal failure compared to those who did not (Figure 2). ${ }^{50}$ This increase in costs for patients with renal failure was driven by significantly higher mechanical ventilation (12 vs 7.8 days) and intensive care unit (13.5 vs 10 days) days. Although the number of patients who developed renal failure in the ZEPHyR trial was low overall $(n=43)$, fewer linezolid $(n=9)$ than vancomycin $(n=34)$ treated patients developed renal failure $(P<0.001)$. 
Table 3 Meta-analyses results for studies comparing linezolid and vancomycin therapy in patients with gram-positive pneumonia

\begin{tabular}{|c|c|c|c|c|c|}
\hline \multirow[t]{2}{*}{ Reference } & \multirow[t]{2}{*}{ Studies, $\mathrm{n}$} & \multicolumn{2}{|c|}{ Patients, $n / \mathbf{N}^{a}$} & \multirow[t]{2}{*}{ Outcome LIN vs VAN ${ }^{b}$} & \multirow[t]{2}{*}{$P$-value } \\
\hline & & LIN & VAN & & \\
\hline \multirow{8}{*}{ Wang et a ${ }^{49}$} & 9 & 551 & 519 & Clinical cure: RR I.08 (0.98-I.18) & 0.11 \\
\hline & 4 & 171 & 163 & MRSA clinical cure: RR I.I6 (0.95-I.43) & 0.15 \\
\hline & 7 & 318 & 282 & Micro success: RR I.I2 (0.96-I.30) & 0.15 \\
\hline & 6 & 130 & 107 & MRSA eradication: RR I.16 (0.93-I.45) & 0.19 \\
\hline & 4 & 1,196 & $\mathrm{I}, 156$ & Mortality: RR 0.88 (0.74-I.05) & 0.16 \\
\hline & 4 & 1,196 & 1,156 & Nephrotoxicity: RR 0.50 (0.3I-0.8I) & 0.005 \\
\hline & 4 & 1,196 & $\mathrm{I}, 156$ & Thrombocytopenia: RR $0.77(0.35-1.60)$ & 0.51 \\
\hline & 4 & 1,196 & $\mathrm{I}, 156$ & Gastrointestinal effects: RR I.33 (0.76-2.34) & 0.32 \\
\hline \multirow[t]{6}{*}{ Jiang et $\mathrm{al}^{44}$} & 10 & $380 / 605$ & $328 / 544$ & Tx success: RR I.09 (95\% Cl: 0.99-I.I9) & 0.07 \\
\hline & 8 & $234 / 391$ & $196 / 375$ & Micro success: RR I.I6 (95\% Cl: I.02-I.3I) & 0.02 \\
\hline & $12^{\mathrm{c}}$ & NR & NR & Mortality: RR 0.95 (95\% Cl: 0.83-I.09) & 0.46 \\
\hline & $9^{c}$ & NR & NR & Anemia: RR I. 14 (95\% Cl: 0.73-I.79) & 0.55 \\
\hline & $9^{c}$ & NR & NR & Thrombocytopenia: RR I.58 (95\% Cl: 0.75-3.33) & 0.23 \\
\hline & $9^{c}$ & NR & NR & Renal: RR $0.4 \mathrm{I}$ (95\% Cl: 0.27-0.64) & $<0.001$ \\
\hline \multirow[t]{4}{*}{ Bally et $\mathrm{al}^{40}$} & 3 & $240 / 563$ & $217 / 527$ & Clin success: OR I.06 (95\% Cl: 0.75-I.5I) & NR \\
\hline & $2^{\mathrm{d}}$ & II4/209 & $106 / 23 \mid$ & Clin success MRSA: OR I.37 (95\% Cl: 0.72-2.44) & NR \\
\hline & 3 & $N R / I, 021$ & $N R / 1,082$ & Mortality: OR 0.85 (95\% Cl: 0.58-I.22) & NR \\
\hline & 3 & NR/874 & NR/852 & Serious AE: OR 0.93 (95\% Cl: 0.62-I.32) & NR \\
\hline Beibei et $\mathrm{a}^{41}$ & 7 & $253 / 398$ & $229 / 360$ & Clin success: OR I.16 (95\% Cl: 0.85, I.57) & NR \\
\hline \multirow[t]{3}{*}{ Lin et $\mathrm{al}^{47, \mathrm{e}}$} & 7 & NR & NR & Clin success: OR I.I I (95\% Cl: 0.82-I.53) & $>0.05$ \\
\hline & 7 & NR & NR & Mortality: OR 0.80 (95\% Cl: 0.59-I.07) & $>0.05$ \\
\hline & 7 & NR & NR & AE: OR I.06 (95\% Cl: 0.68-I.64) & $>0.05$ \\
\hline
\end{tabular}

Notes: an Equals number of successfully treated patients, $\mathrm{N}$ equals the total number of patients; data presented as number of successfully treated patients; ${ }^{b}$ data presented as OR or RR $(95 \% \mathrm{Cl})$; ' comparison between linezolid and glycopeptides; 'patients with confirmed MRSA pneumonia; ${ }^{e}$ article published in Chinese; data obtained from English abstract.

Abbreviations: AE, adverse event; Clin, clinical; Cl, confidence interval; LIN, linezolid; Micro, microbiologic; NR, not reported; RR, risk ratio; Tx, treatment; VAN, vancomycin; MRSA, methicillin-resistant Staphylococcus aureus; OR, odds ratio.

\section{Post hoc ZEPHyR analysis: Chinese perspective}

Data from four cities representing geographical areas in the North (Beijing), South (Guangzhou), East (Nanjing), and West (Xi'an) were utilized to capture economic and clinical differences in treating patients with nosocomial pneumonia in the People's Republic of China. ${ }^{9}$ Total treatment costs were highest in Guangzhou and lowest in Xi'an; total treatment costs for linezolid and vancomycin therapy were similar when compared within each city (Figure 3). Results from this analysis show a tradeoff between costs and effectiveness for

Linezolid $(\mathrm{n}=224) \quad$ Vancomycin $(\mathrm{n}=224)$

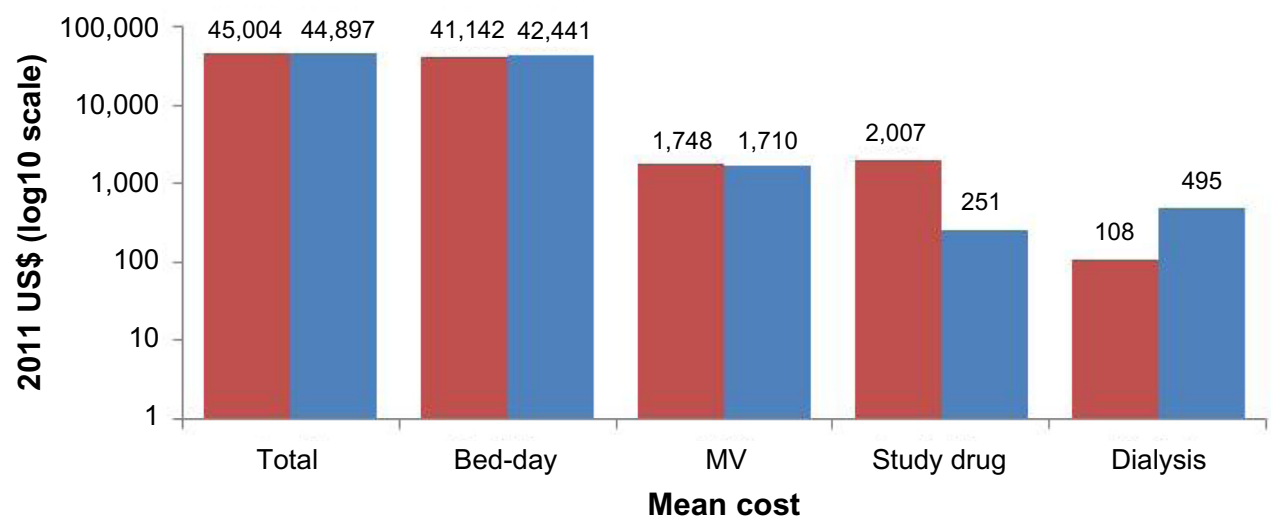

Figure I Mean cost by treatment for patients enrolled in the ZEPHyR trial (modified intent-to-treat population).

Note: Reprinted from Clinical Therapeutics, 36(9), Niederman MS, Chastre J, Solem CT, et al, Health economic evaluation of patients treated for nosocomial pneumonia caused by methicillin-resistant Staphylococcus aureus: secondary analysis of a multicenter randomized clinical trial of vancomycin and linezolid, I233-1243. Copyright 20I4, with permission from Elsevier..$^{50}$

Abbreviation: MV, mechanical ventilation. 


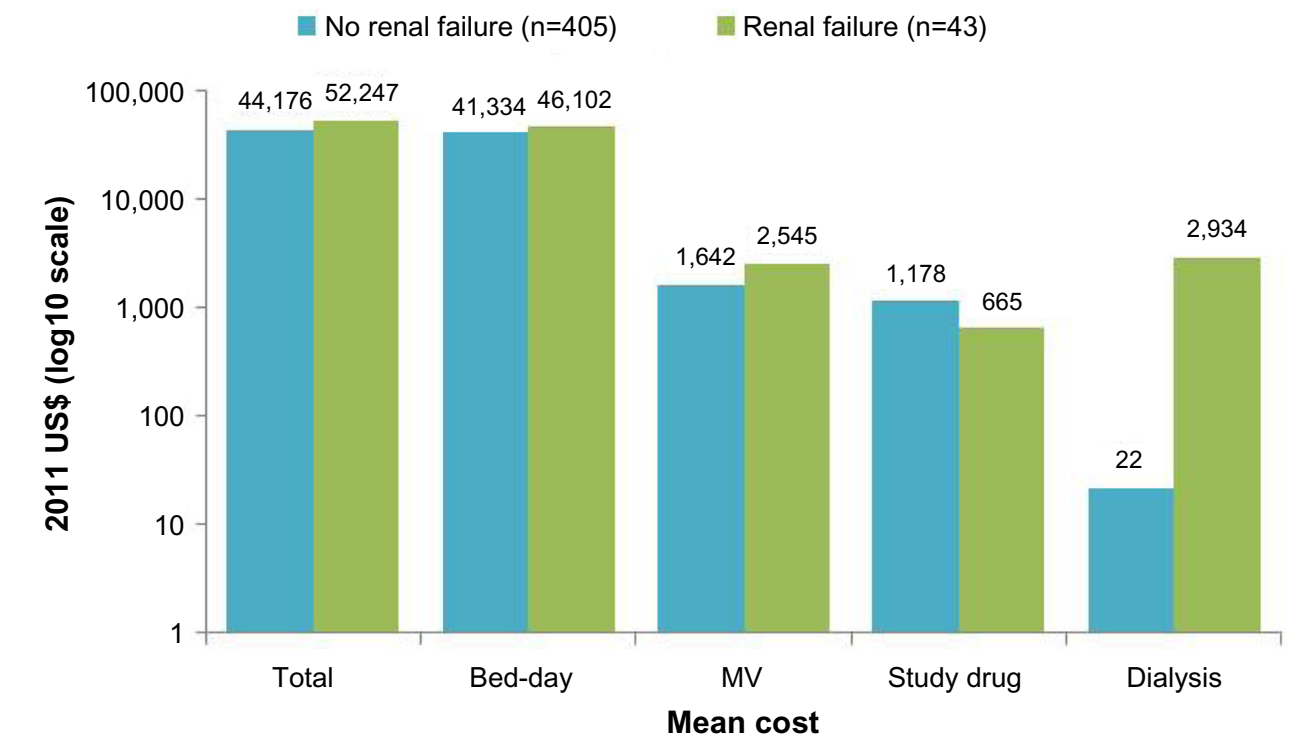

Figure 2 Mean cost by renal failure status for patients enrolled in the ZEPHyR trial (modified intent-to-treat population).

Note: Reprinted from Clinical Therapeutics, 36(9), Niederman MS, Chastre J, Solem CT, et al, Health economic evaluation of patients treated for nosocomial pneumonia caused by methicillin-resistant Staphylococcus aureus: secondary analysis of a multicenter randomized clinical trial of vancomycin and linezolid, I233-1243. Copyright 2014, with permission from Elsevier. ${ }^{50}$

Abbreviation: MV, mechanical ventilation.

tier 3A hospitals located in Beijing, Guangzhou, Nanjing, and Xi'an.

Total inpatient costs were similar between linezolid and vancomycin therapy in all four cities evaluated. Total inpatient costs for linezolid ranged from $¥ 58,835$ to $¥ 86,894$ and for vancomycin $¥ 58,390$ to $¥ 87,033$. Analysis by city shows that linezolid compared to vancomycin therapy was dominant in Guangzhou, meaning linezolid compared to vancomycin therapy had a higher probability of treatment success with lower total treatment costs. Linezolid therapy was associated with an incremental cost-effectiveness ratio of $¥ 1,861$ in Beijing, $¥ 163$ in Nanjing, and $¥ 16,509$ in Xi’an. Results for sensitivity analyses suggested by Chinese clinical experts show that linezolid dominated vancomycin therapy for many of the scenarios evaluated in all four cities.

\section{Retrospective analysis}

Results from a retrospective analysis conducted in Shanghai, People's Republic of China, were similar to those previously reported. ${ }^{11}$ Although drug costs were higher for linezolid compared to vancomycin therapy, median total hospital costs for linezolid ( $¥ 133,825$ ) and vancomycin ( $¥ 113,160$; $P=0.076$ ) therapy for patients with HAP did not significantly differ.

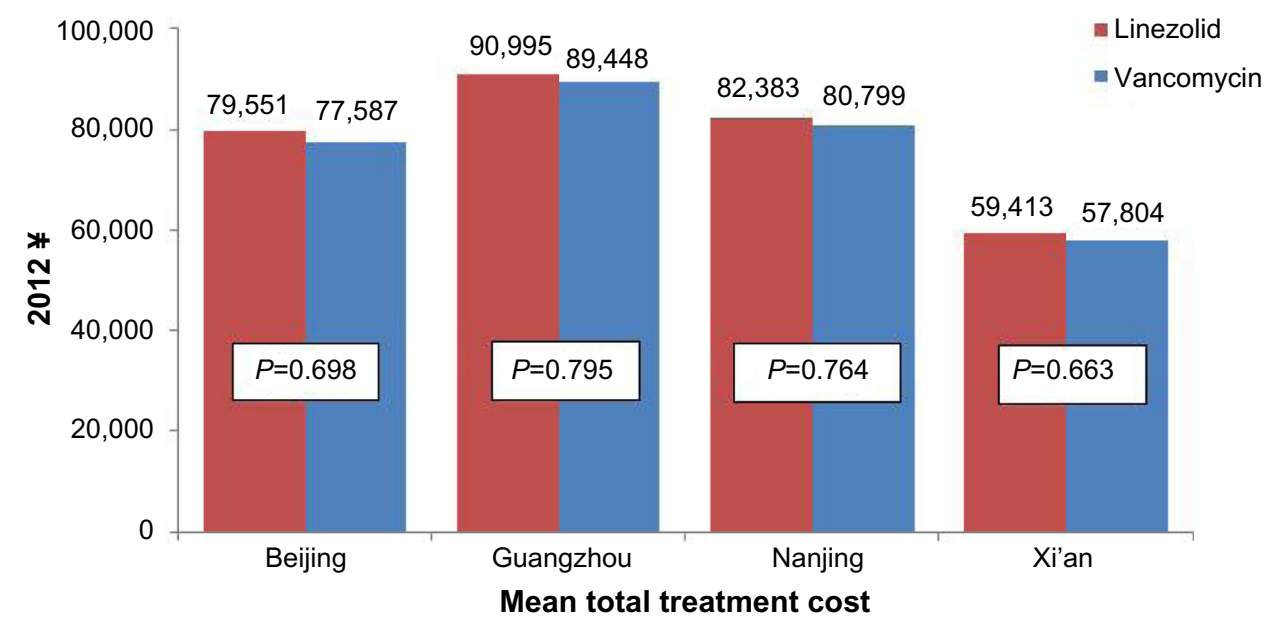

Figure 3 Mean cost by treatment for linezolid and vancomycin therapy in Beijing, Guangzhou, Nanjing, and Xi'an, the People's Republic of China. Note: Courtesy of Wan et al. ${ }^{9}$ 


\section{Conclusion}

Hospitalized patients with MRSA nosocomial pneumonia have few treatment options. Historically, this patient population was treated with intravenous vancomycin therapy. Published evidence from both clinical studies and metaanalyses suggest similar if not better outcomes for patients with MRSA nosocomial pneumonia treated with linezolid compared to vancomycin therapy. Evidence from economic studies, including those conducted from a Chinese perspective, suggests that linezolid is a cost-effective therapy for hospitalized patients with MRSA nosocomial pneumonia. Both clinical and economic evidence supports the use of linezolid for the treatment of patients with MRSA nosocomial pneumonia.

\section{Disclosure}

Pfizer Investment Co. Ltd provided financial support to Pharmerit International for manuscript development. Pharmerit International retained independent control not only of studies included and reviewed in this manuscript but also analysis of data obtained from those studies. B Lesher and $\mathrm{X}$ Gao are employees of Pharmerit International. Y Chen is an employee of Pfizer Investment Co. Ltd, Beijing, People's Republic of China. Z Liu has served as a speaker for Pfizer Investment Co. Ltd. The authors report no other conflicts of interest in this work.

\section{References}

1. World Health Organization. Antimicrobial Resistance: Global Report on Surveillance. 2014. Available from: http://apps.who.int/iris/bitstream/ 10665/112642/1/9789241564748_eng.pdf?ua=1. Accessed February 10, 2015.

2. Pletz MW, Burkhardt O, Welte T. Nosocomial methicillin-resistant Staphylococcus aureus (MRSA) pneumonia: linezolid or vancomycin?Comparison of pharmacology and clinical efficacy. Eur J Med Res. 2010;15(12):507-513

3. Chung DR, Song JH, Kim SH, et al. High prevalence of multidrugresistant nonfermenters in hospital-acquired pneumonia in Asia. Am J Respir Crit Care Med. 2011;184(12):1409-1417.

4. Liu YN, Cao B, Wang H, et al. [Adult hospital acquired pneumonia: a multicenter study on microbiology and clinical characteristics of patients from 9 Chinese cities]. Zhonghua Jie He He Hu Xi Za Zhi. 2012;35(10):739-746

5. Zhang Y, Yao Z, Zhan S, et al. Disease burden of intensive care unitacquired pneumonia in China: a systematic review and meta-analysis. Int J Infect Dis. 2014;29:84-90.

6. Chen HB, Zhao CJ, Wang H, et al. [An analysis of resistance of nosocomial infection pathogens isolated from 13 teaching hospitals in 2011] Zhonghua Nei Ke Za Zhi. 2013;52(3):203-212.

7. Zhao C, Sun H, Wang H, et al. Antimicrobial resistance trends among 5608 clinical gram-positive isolates in China: results from the grampositive cocci resistance surveillance program (2005-2010). Diagn Microbiol Infect Dis. 2012;73(2):174-181.

8. Wunderink RG, Niederman MS, Kollef MH, et al. Linezolid in methicillin-resistant Staphylococcus aureus nosocomial pneumonia: a randomized, controlled study. Clin Infect Dis. 2012;54(5):621-629.
9. Wan Y, Li Q, Chen Y, Haider S, Liu S, Gao X. Economic analysis from a Chinese Payer's perspective within a randomized clinical trial of linezolid-versus vancomycin-treated patients with nosocomial pneumonia caused by methicillin resistant Staphylococcus aureus (MRSA-NP). Paper presented at: Society for Medical Decision Making Asia-Pacific Conference; January 7, 2014; Singapore.

10. Peyrani P, Wiemken TL, Kelley R, et al. Higher clinical success in patients with ventilator-associated pneumonia due to methicillinresistant Staphylococcus aureus treated with linezolid compared with vancomycin: results from the IMPACT-HAP study. Crit Care. 2014; 18(3):R118.

11. Song Y, Yang Y, Chen W, et al. Clinical response and hospital costs associated with the empirical use of vancomycin and linezolid for hospital-acquired pneumonia in a Chinese tertiary care hospital: a retrospective cohort study. Clinicoecon Outcomes Res. 2014;6:451-461.

12. Chen X, Wang WK, Han LZ, et al. Epidemiological and genetic diversity of Staphylococcus aureus causing bloodstream infection in Shanghai, 2009-2011. PLoS One. 2013;8(9):e72811.

13. Jones RN, Castanheira M, Hu B, et al. Update of contemporary antimicrobial resistance rates across China: reference testing results for 12 medical centers (2011). Diagn Microbiol Infect Dis. 2013;77(3):258-266.

14. LuY, LiY, Xue F, et al. [Analysis of resistance tendency of bloodstreaminfecting pathogens in China]. Zhonghua Jie He He Hu Xi Za Zhi. 2013;36(6):411-419.

15. Reinert RR, Low DE, Rossi F, Zhang X, Wattal C, Dowzicky MJ. Antimicrobial susceptibility among organisms from the Asia/Pacific Rim, Europe and Latin and North America collected as part of TEST and the in vitro activity of tigecycline. JAntimicrob Chemother. 2007;60(5): 1018-1029.

16. Sun HL, Wang H, Chen MJ, et al. [An antimicrobial resistance surveillance of gram-positive cocci isolated from 12 teaching hospitals in China in 2009]. Zhonghua Nei Ke Za Zhi. 2010;49(9):735-740.

17. Wang H, Liu Y, Sun H, Xu Y, Xie X, Chen M. In vitro activity of ceftobiprole, linezolid, tigecycline, and 23 other antimicrobial agents against Staphylococcus aureus isolates in China. Diagn Microbiol Infect Dis. 2008;62(2):226-229.

18. Wei L, Wu R, Zou F, et al. Antibiotic resistance pattern of methicillinresistance and coagulase-negative Staphylococcus isolates among hospitalized patients at a tertiary hospital in Gansu, North-western China. Afr J Microbiol Res. 2014;8(1):105-108.

19. Zou MX, Zhou RR, Wu WJ, et al. Antimicrobial resistance and molecular epidemiological characteristics of clinical isolates of Staphylococcus aureus in Changsha area. Chin Med J (Engl). 2012;125(13) 2289-2294.

20. Hu FP, Zhu D, Wang F, et al. 2011 CHINET surveillance of bacterial resistance in China. Chin J Infect Chemother. 2012;12(5): 321-329.

21. Zheng B, LV Y. Ministry of Health National Antimicrobial Resistance Investigation Net Annual Report of 2011: antimicrobial resistance surveillance of gram-positive cocci. Chin J Clin Pharmacol. 2012; 28(12):888-892.

22. Song JH, Asian Hospital Acquired Pneumonia Working G. Treatment recommendations of hospital-acquired pneumonia in Asian countries: first consensus report by the Asian HAP Working Group. Am J Infect Control. 2008;36(4 Supp1):S83-S92.

23. Cao B, Tan TT, Poon E, et al. Consensus statement on the management of methicillin-resistant Staphylococcus aureus nosocomial pneumonia in Asia. Clin Respir J. 2015;9(2)129-142.

24. American Thoracic Society, Infectious Diseases Society of America. Guidelines for the management of adults with hospital-acquired, ventilator-associated, and healthcare-associated pneumonia. Am J Respir Crit Care Med. 2005;171(4):388-416.

25. Liu C, Bayer A, Cosgrove SE, et al. Clinical practice guidelines by the Infectious Diseases Society of America for the treatment of methicillinresistant Staphylococcus aureus infections in adults and children: executive summary. Clin Infect Dis. 2011;52(3):285-292. 
26. National Institute for Health and Care Excellence. Pneumonia: Diagnosis and Management of Community-and Hospital-acquired Pneumonia in Adults. 2014; Available from: http://www.nice.org.uk/guidance/ cg191/documents/pneumonia-guideline-consultation-full-guideline2. Accessed February 12, 2015.

27. Zhuo C, Xu YC, Xiao SN, Zhang GY, Zhong NS. Glycopeptide minimum inhibitory concentration creep among meticillin-resistant Staphylococcus aureus from 2006-2011 in China. Int J Antimicrob Agents. 2013;41(6):578-581.

28. Rybak MJ, Lomaestro BM, Rotschafer JC, et al. Vancomycin therapeutic guidelines: a summary of consensus recommendations from the Infectious Diseases Society of America, the American Society of Health-System Pharmacists, and the Society of Infectious Diseases Pharmacists. Clin Infect Dis. 2009;49(3):325-327.

29. Mendes RE, Hogan PA, Streit JM, Jones RN, Flamm RK. Zyvox ${ }^{\circledR}$ Annual Appraisal of Potency and Spectrum (ZAAPS) program: report of linezolid activity over 9 years (2004-2012). JAntimicrob Chemother. 2014;69(6):1582-1588.

30. Mendes RE, Hogan PA, Streit JM, Jones RN, Flamm RK. Update on linezolid in vitro activity through the Zyvox Annual Appraisal of Potency and Spectrum Program, 2013. Antimicrob Agents Chemother. 2015;59(4):2454-2457.

31. Rubinstein E, Cammarata S, Oliphant T, Wunderink R. Linezolid (PNU100766) versus vancomycin in the treatment of hospitalized patients with nosocomial pneumonia: a randomized, double-blind, multicenter study. Clin Infect Dis. 2001;32(3):402-412.

32. Wunderink RG, Cammarata SK, Oliphant TH, Kollef MH. Continuation of a randomized, double-blind, multicenter study of linezolid versus vancomycin in the treatment of patients with nosocomial pneumonia. Clin Ther. 2003;25(3):980-992.

33. Wunderink RG, Rello J, Cammarata SK, Croos-Dabrera RV, Kollef MH. Linezolid vs vancomycin: analysis of two double-blind studies of patients with methicillin-resistant Staphylococcus aureus nosocomial pneumonia. Chest. 2003;124(5):1789-1797.

34. Kollef MH, Rello J, Cammarata SK, Croos-Dabrera RV, Wunderink RG. Clinical cure and survival in gram-positive ventilator-associated pneumonia: retrospective analysis of two double-blind studies comparing linezolid with vancomycin. Intensive Care Med. 2004;30(3):388-394.

35. Lin DF, Zhang YY, Wu JF, et al. Linezolid for the treatment of infections caused by gram-positive pathogens in China. Int J Antimicrob Agents. 2008;32(3):241-249.

36. Stevens DL, Herr D, Lampiris H, Hunt JL, Batts DH, Hafkin B. Linezolid versus vancomycin for the treatment of methicillin-resistant Staphylococcus aureus infections. Clin Infect Dis. 2002;34(11): 1481-1490.

37. Wunderink RG, Mendelson MH, Somero MS, et al. Early microbiological response to linezolid vs vancomycin in ventilator-associated pneumonia due to methicillin-resistant Staphylococcus aureus. Chest. 2008;134(6):1200-1207.

38. Caffrey AR, Morrill HJ, Puzniak LA, Laplante KL. Comparative effectiveness of linezolid and vancomycin among a national veterans affairs cohort with methicillin-resistant Staphylococcus aureus pneumonia. Pharmacotherapy. 2014;34(5):473-480.
39. Chan JD, Pham TN, Wong J, et al. Clinical outcomes of linezolid vs vancomycin in methicillin-resistant Staphylococcus aureus ventilatorassociated pneumonia: retrospective analysis. $J$ Intensive Care Med. 2011;26(6):385-391.

40. Bally M, Dendukuri N, Sinclair A, Ahern SP, Poisson M, Brophy J. A network meta-analysis of antibiotics for treatment of hospitalised patients with suspected or proven meticillin-resistant Staphylococcus aureus infection. Int J Antimicrob Agents. 2012; 40(6):479-495.

41. Beibei L, Yun C, Mengli C, Nan B, Xuhong Y, Rui W. Linezolid versus vancomycin for the treatment of gram-positive bacterial infections: meta-analysis of randomised controlled trials. Int J Antimicrob Agents. 2010;35(1):3-12.

42. Falagas ME, Siempos II, Vardakas KZ. Linezolid versus glycopeptide or beta-lactam for treatment of gram-positive bacterial infections: meta-analysis of randomised controlled trials. Lancet Infect Dis. 2008;8(1):53-66

43. Fu J, Ye X, Chen C, Chen S. The efficacy and safety of linezolid and glycopeptides in the treatment of Staphylococcus aureus infections. PLoS One. 2013;8(3):e58240.

44. Jiang H, Tang RN, Wang J. Linezolid versus vancomycin or teicoplanin for nosocomial pneumonia: meta-analysis of randomised controlled trials. Eur J Clin Microbiol Infect Dis. 2013;32(9): $1121-1128$.

45. Kalil AC, Klompas M, Haynatzki G, Rupp ME. Treatment of hospitalacquired pneumonia with linezolid or vancomycin: a systematic review and meta-analysis. BMJ Open. 2013;3(10):e003912.

46. Kalil AC, Murthy MH, Hermsen ED, Neto FK, Sun J, Rupp ME. Linezolid versus vancomycin or teicoplanin for nosocomial pneumonia: a systematic review and meta-analysis. Crit Care Med. 2010; 38(9): 1802-1808.

47. Lin ZQ, Huang YL, Huang P, Chen Q. [Linezolid versus vancomycin in the treatment of pneumonia caused by gram-positive cocci: metaanalysis of randomised controlled trials]. Zhonghua Jie He He Hu Xi Za Zhi. 2010;33(12):900-906.

48. Walkey AJ, O'Donnell MR, Wiener RS. Linezolid vs glycopeptide antibiotics for the treatment of suspected methicillin-resistant Staphylococcus aureus nosocomial pneumonia: a meta-analysis of randomized controlled trials. Chest. 2011;139(5):1148-1155.

49. Wang Y, Zou Y, Xie J, et al. Linezolid versus vancomycin for the treatment of suspected methicillin-resistant Staphylococcus aureus nosocomial pneumonia: a systematic review employing meta-analysis. Eur J Clin Pharmacol. 2015;71(1):107-115.

50. Niederman MS, Chastre J, Solem CT, et al. Health economic evaluation of patients treated for nosocomial pneumonia caused by methicillinresistant Staphylococcus aureus: secondary analysis of a multicenter randomized clinical trial of vancomycin and linezolid. Clin Ther. 2014; 36(9):1233-1243.

51. Tan SC, Wang X, Wu B, et al. Cost-effectiveness of linezolid versus vancomycin among patients with methicillin-resistant Staphylococcus aureus confirmed nosocomial pneumonia in China. Value Health Reg Issue. 2014;3:94-100.
ClinicoEconomics and Outcomes Research

\section{Publish your work in this journal}

ClinicoEconomics \& Outcomes Research is an international, peerreviewed open-access journal focusing on Health Technology Assessment, Pharmacoeconomics and Outcomes Research in the areas of diagnosis, medical devices, and clinical, surgical and pharmacological intervention. The economic impact of health policy and health systems

\section{Dovepress}

organization also constitute important areas of coverage. The manuscript management system is completely online and includes a very quick and fair peer-review system, which is all easy to use. Visit http://www.dovepress.com/testimonials.php to read real quotes from published authors. 